\title{
Article
}

\section{Employing Evidence: Does it have a Job in Vocational Libraries?}

\author{
Cecily Martina \\ Liaison Librarian, Southbank Institute \\ Briabane, Queensland, Australia \\ E-mail: Cecily.e.martina@det.qld.gov.au \\ Brad Jones \\ Liaison Librarian, Bremer Institute of TAFE \\ Queensland, Australia \\ E-mail: Bradley.jones@det.qld.gov.au
}

Received: 15 December 2005

Accepted: 6 March 2006

\begin{abstract}
(C) 2006 Martina and Jones. This is an Open Access article distributed under the terms of the Creative Commons Attribution License (http://creativecommons.org/licenses/by/2.0), which permits unrestricted use, distribution, and reproduction in any medium, provided the original work is properly cited.
\end{abstract}

\begin{abstract}
Objective - Evidence based librarianship (EBL) springs from medical and academic origins. As librarians are tertiary educated (only occasionally with supplementary qualifications covering research and statistics) EBL has had an academic focus. The EBL literature has significant content from school and university perspectives, but has had little, if any, vocational content. This paper suggests a possible Evidence Based Librarianship context for vocational libraries.
\end{abstract}

Methods - A multidisciplinary scan of evidence based literature was undertaken, covering medicine and allied health, librarianship, law, science and education. National and international vocational education developments were examined. The concept and use of evidence in vocational libraries was considered.

Results - Library practice can generally benefit from generic empirical science methodologies used elsewhere. Different areas, however, may have different concepts of what constitutes evidence and appropriate methodologies. Libraries also need to reflect the evidence used in their host organisations. The Australian vocational librarian has been functioning in an evidence based educational sector: national, transportable, prescriptive, competency based and outcome driven Training Packages. These require a qualitatively different concept of evidence compared to other educational sectors as they reflect pragmatic, economic, employability outcomes.

Conclusions - Vocational and other librarians have been doing research but need to be more systematic about design and analysis. Librarians need to develop 'evidence literacy' as one of their professional evaluation skills. Libraries will need to utilise evidence relevant to their host organisations to establish and maintain credibility, and in the vocational sector this is set in a competency based framework. Competency 
based measures are becoming increasingly relevant in school and university (including medical) education.

\section{Librarians: generic and specialist evidence skills?}

Whilst evidence based philosophies have been with us for some time, the current evolving debate over the nature and practical application of evidence in librarianship is relatively recent.

In Australia, librarians are tertiary educated and for the most part move in generalist circles (public, vocational and university for example). Sectors such as health and law have a history of speciality, and there are even areas like teacher librarianship where the library qualification is secondary. Some librarians hold additional qualifications including research components (Partridge and Hallam "Developing a Culture of Evidence Based Practice"), but library education itself has only relatively recently increased its focus on research methodology and statistics.

After moving into the library workforce it is reasonable to suggest that librarians absorb something of the culture and skill set of their host organisations due to the sharing of goals, collaboration with nonlibrary colleagues and the information with which they deal. In some cases this involves research and statistics. This may in part explain the emergence of interest in evidence based librarianship (EBL) in health and academic libraries, both of which exist in research rich environments.

The medical fraternity is often critical of the evidence base behind work done in its own area, due to factors such as the quality of the work itself, the interpretation of evidence, or contamination by vested economic interests (Ioannidis; Smith). Evidence Based Medicine (EBM) itself has not been universally or uncritically accepted in medical \& allied areas (Straus and McAlister; Grahame-Smith).
There is also an argument that, contrary to the simplified view that some areas have failed to capitalise on more advanced research methods, different "evidence" may apply in different fields. One significant difference, for example, has been a comparison with the legal concept of evidence - particularly the challenges posed by the Daubert decision and 'good science' implications (Berger; Wagner). The countering of scientific argument to serve vested interests reminds us that evidence has its place - often behind political and economic interests. Given the adversarial host culture, legal librarians may have different views of evidence.

Educators also have different perspectives on evidence. Groundwater-Smith goes so far as to "argue that education can lay claim to a broader and richer understanding of [evidence based practice] growing out of a tradition of action enquiry and practitioner research." Todd raises the relevance of the host organisation when he suggests that evidence must demonstrate the contribution of the library to the school's learning goals, through a constructivist, inquiry based framework, at the local level.

It may also be argued that evidence varies not only between disciplines, but within different sectors of the same basic discipline, such as education. Outside the school setting, Partridge and Hallam ("Developing a Culture of Evidence Based Practice") examined the University level training of professional librarians. Their preferred educational outcome favoured the evidence based "reflective practitioner" rather than researcher (except at Research Masters and PhD levels). They noted difficulties in keeping courses relevant to employers' needs, increased curriculum congestion, ongoing review of the curriculum at their institution, and invite "other teaching and 
learning models (to be) presented and critically discussed."

The Partridge and Hallam study did not include the views of Vocational Education and Training (VET) librarians. This sector does not have as significant a research and publication culture as medicine and academia. The post-compulsory vocational education sector reflects a different and increasingly relevant teaching and learning model, with a very different perspective on what constitutes evidence.

It is important to move beyond medicine and academia to more accurately reflect reality. Table 1 displays the significance of the VET sector in Australia While not having the profile of medicine and academia, VET qualifications are held by nearly a third of the Australian working age population, and it has a participation rate almost twice that of the tertiary sector. The pervasiveness of VET training seems to give it a degree of invisibility. As the training sector underpinning the economy, the authors believe that this area, and its concept of evidence, warrants attention and also has a considerable amount to offer.

VET librarians train at University and are familiar with academic assessment.

However, they work in the same sector that trains paraprofessionals according to a very different competency based regime. Professionals and paraprofessionals, however, often do quite similar work. Teece (quoted in Partridge and Hallam "The Double Helix") notes that paraprofessionals are now "routinely doing quite complex work formerly seen as exclusively the province of professional librarians" (1). Carroll states "one of the key dilemmas that has faced the library industry...has been the degree to which the two sectors of library employment converge" (117). VET sector librarians must live with the discomfort of differing emphasis on serving goals related to supply-driven liberal holistic education ends (as with their own training) and demand-driven pragmatic employability outcomes (as with paraprofessionals).

While there are international variants, the competency based approach is the preferred vocational education option in competitive economies. In Australia, the VET sector differs from other educational sectors in that:

- ties with industry needs are built into the system, as curricula are determined and regularly reviewed by industry (via Industry Skills Councils);

- curricula are not developed in individual institutions. Instead, highly prescriptive, nationally consistent Training Packages are used; and,

- assessment is not on the basis of holistic measures, but on explicitly defined competencies using "evidence guides.

\begin{tabular}{|l|l|l|}
\hline How significant is Vocational Education and Training? \\
\hline $\begin{array}{l}\text { Qualifications held } 2004 \\
\text { (15-64 age group) }\end{array}$ & Bachelor degree or above & $18.9 \%$ \\
\hline $\begin{array}{l}\text { Participation rates } \\
(2003)\end{array}$ & University & $31.3 \%$ \\
\hline
\end{tabular}

Table 1: Significance of VET in Australia 
The authors are of the view that relevant evidence reflects the generic / discipline based skills debate (Partridge and Hallam "The Double Helix"; Smith and Martina). In this sense, generic scientific methodologies, research strategies and statistical analyses applied in areas such as agriculture, psychology and medicine might also be directly applied in librarianship. Many disciplines, however, may also have their own unique perspectives on what constitutes evidence, and these may require different approaches to be taken by libraries servicing these areas.

EBL may need to consider both a "generic" science based perspective, as well as a "host discipline" relevancy approach to evidence. EBL relies on the argument that up until now librarianship has lacked a sophisticated "generic" science base, relying instead on lower levels of evidence. "We often espouse the deficiency of our users' information literacy yet we too have deficiencies and particularly with regard to research" (Macauley). Eldredge laments "that librarianship does not offer a better representation of the more rigorous methods at the higher levels of evidence" (298). "Librarians place a great emphasis on anecdote and experience" (Brice, Booth and Bexon 16), with approaches such as case studies resulting in an "overwhelming positive-outcome bias" (Eldredge 297). EBL should result in "an increased number of research projects conducted at the higher levels of evidence that are capable of facilitating practical decisions" (Eldredge 298).

Library practitioners outside medicine and academia may find this empirical science basis unfamiliar, with a resultant tendency to fall back on a rebadging of literature research and traditional library approaches as evidence. This misses the primary point of EBL: that more sophisticated methodological and statistical analysis of what goes on in libraries is required.
The "discipline" based approach within a host organisation is a different concept. In educational libraries, evidence should reflect the accepted evidence in education, particularly attending to the forms of assessment used in each sector. To this end, school and university levels are primarily holistic, while VET has for some time been shifting to highly prescriptive economic approach measures. Further, this approach has been widely accepted globally (Kearns) and aspects are moving into other educational and professional development arenas. This is a pivotal development for the concept of evidence across all educational sectors and, consequently, for librarians in these educational areas.

\section{A brief history of vocational education in Australia}

It may be helpful to provide a brief historical background of VET, examine the current VET structure, touch upon some recent library examples, and reflect upon the potential role of evidence in the vocational context.

The male-trade stereotype of the Australian VET sector dominated until the 1960's and 70s. While the stereotype persists, the reality faded due to international social and economic changes, with its Australian variant appearing in the landmark 1974 Kangan report, which effectively combined the various state VET agencies into a new national educational sector. "For the first time, TAFE [Technical and Further Education] was regarded as part of the tertiary education sector" (Employment and Skills Formation Council, quoted in Australian Education Union).

In the late 1980s, with vocational education also receiving much attention overseas, there was a significant shift from liberal education goals to a solid economically driven agenda, though again with an Australian flavour. The Australian National Training Authority (ANTA) was established in 1992 with heavy industry involvement. User choice saw private 
businesses supplement the public TAFE system. Globalisation, with international movements of capital and skills, encouraged pragmatic vocational education and various countries repositioned their training systems for this new environment.

The late 1990s brought the National Training Framework, a national approach to qualifications through industry-defined competencies and the development of Training Packages. ANTA was abolished and its functions subsumed by the Department of Education Science and Training (DEST), with a new direction outlined in DEST's Skilling Australia paper. This builds on the competencies and Training Package concept, with training policies, priorities and delivery driven by industry and business needs, as well as greater flexibility emphasising employability skills and a revision of quality control measures.

\section{The current basis of vocational education}

The vocational sector, while still retaining liberal holistic goals relating to the development of individual potential, has had a significant international shift in primary emphasis back to pragmatic economic outcomes. Mammon effectively drives vocational education. There is little doubt about potential conflicts of interest, or motivation for evidence to be doctored.

Educational qualifications in Australia are detailed under the Australian Qualifications Framework (see Table 2). This framework connects the schools, VET and higher education sectors in a single framework, and details qualification titles and guidelines. While assessments at school and university tend to the holistic, the VET sector takes on an approach based on 'competence' within a 'Training Packages' context. The content agenda is driven by business and industry via Industry Skills Councils.

The Australian Training Package arrangements are detailed on the National Training Information Service's website $<$ http://www.ntis.gov.au/>. Training Packages are highly prescriptive in that they outline all the competencies considered relevant to a particular industry grouping. Qualifications can be at different levels; each qualification is made up of a package of competencies; each competency is made up of a number of elements; each element is assessed according to an evidence guide

AQF Table of Qualifications (by sector of accreditation), March 2005

\begin{tabular}{|l|l|l|}
\hline $\begin{array}{l}\text { Schools Sector } \\
\text { Accreditation }\end{array}$ & $\begin{array}{l}\text { Vocational Education and } \\
\text { Training Sector Accreditation }\end{array}$ & $\begin{array}{l}\text { Higher Education Sector } \\
\text { Accreditation }\end{array}$ \\
\hline & & $\begin{array}{l}\text { Doctoral Degree } \\
\text { Masters Degree } \\
\text { Graduate Diploma } \\
\text { Graduate Certificate } \\
\text { Bachelor Degree } \\
\text { Associate Degree, Advanced Diploma } \\
\text { Vocational Graduate Diploma } \\
\text { Vocational Graduate Certificate }\end{array}$ \\
& $\begin{array}{l}\text { Advanced Diploma } \\
\text { Diploma }\end{array}$ & \\
Senior Secondary & Certificate IV & \\
Certificate of Education & Certificate II & \\
& Certificate I & \\
\hline
\end{tabular}

Table 2: The Australian Qualifications Framework Reproduced with permission of the Australian Qualifications Framework Advisory Committee 
(acceptable observable evidence that complies with specific auditable criteria). Thus, the educational evidence is already defined. Industry requires a particular predetermined set of competencies to be available. Individuals may have existing skills acknowledged by recognition of prior learning (RPL). Learners are assessed as either "competent" or "not yet competent". They then work on the remaining competencies until they can demonstrate evidence of achievement. The competencies may be sequenced. If competencies are not achieved, efforts concentrate on bringing individuals up to the specified level. When the packaged requisite set of competencies has been evidenced, a qualification is issued.

This competency based approach has extended to overlap with other sectors. Many students now begin vocational studies in the post-compulsory years of high school, with these studies recognised upon subsequent entry to the VET system. At the higher end, VET has articulation into university courses.

Educational outcomes aside, the entire sector is subject to heavily measured outcomes, accountability and quality assurance processes, and subject to ongoing review. Employer surveys, specific client target groups, student retention and completion rates, student outcomes and earnings, and economic input/output measures all feature. This approach has been described as evidence based education (McDonald). While similar pressures exist in most sectors, in VET they are housed within a competency based context.

\section{The VET experience}

Within the Queensland TAFE sector, Southbank Institute has had considerable involvement with the massive redefinition of skill sets expected of library practitioners. Current and recent library staff have published or presented on a broad range of topics that provide a credible record, irrespective of EBL limitations, for any institution: metadata, the establishment of eLearn centres, the evolving collaborative relationship between librarians and teachers in working towards national VET objectives, digital repositories, information literacy, digital video and free / budget practical software.

Of particular note is a paper by Smith and Martina, which targeted the 'information literacy' needs of bakers. Surveys and other evidence were collected from teachers, business and industry. The correlation between VETs prescriptive evidence based key competencies, information literacy principles and industry sourced "employability skills", showed the interdependence between them and it was concluded that information literacy skills in the workplace are essential. This preliminary study recommended that information literacy should be embedded in training packages, and that librarians be involved in the training package review process. Thus, "by using methods familiar to our colleagues outside librarianship, librarians can open doors to future multidisciplinary collaboration" (Eldredge 292).

\section{Does evidence have a role in vocational libraries?}

The question is, of course, rhetorical, as evidence has several roles in vocational libraries. In the "generic" empirical science sense, all libraries face issues that can benefit from tighter methodologies than have been adopted in the past. Some evidence may come from other disciplines: information literacy instruction, for example, could draw upon work done previously in the broader field of education. Other aspects are undoubtedly unique to libraries, including some specific to vocational libraries, and require original research.

Libraries have faced considerable pressures and changes for quite some time, and this situation shows no sign of abating. To apply higher level scientific experimental designs and statistical 
analyses would require the acceptance of yet another new perspective and skill set. At present there are few signs that this can be achieved within the bounds of everyday librarianship. But these are early days, and efforts may be made toward raising awareness and developing such an "evidence literacy" skill set. There are dangers in yet another brief workplace training session, but in the short term this may well be the most likely option to increase general understanding. It is unlikely that there will be an employment market for specialist, scientifically trained, librarians; and while there has been increased attention on EBL content recently, the development of more structured training electives and research could be further encouraged. Another option is to collaborate with research experts. Ultimately, the application of more evidence based methods must have an impact beyond an increasingly sophisticated audience of professional librarians.

Turning to the second major aspect of evidence in vocational (and other) libraries, their ultimate credibility and possibly survival may depend upon adopting the educational variants of evidence used by the libraries' respective host institutions. The evidence used in Australian vocational institutions is different to that adopted in school and university education. At present, and for the foreseeable future, evidence is based on the concept of competencies. Vocational librarians need to be able to dissect the Training Packages, identify those competencies where they may be able to partly or wholly make a contribution, and examine the evidence guides for measuring these competencies. Thereafter, librarians will need to work these into an analytical, methodological and statistical framework in order to produce usable, relevant evidence. They might also be on the alert for gaps in competencies and employability skills, and lobby for inclusions or variation in these areas.

While educational evidence may relate to competencies, other evidence is also of critical relevance in VET, though it remains set in a competency based, pragmatic economic outcomes framework. These are the organisational performance evaluations such as employer surveys, retention and completion rates, and economic cost /benefit measures. Following from McDonald, in 2003 Dawe (8) made specific reference to the influence of EBM, and provided advance notice of a National Council for Vocational Education Research (NCVER) centralised resource for VET systematic reviews. In 2005, Thomson, Anlezark, Dawe and Hayman advised that they had undertaken "the first systematic review conducted in a vocational education and training ... context in Australia" (9), and Anlezark, Dawe and Hayman concurrently developed "a replicable framework and infrastructure for further systematic reviews of research" (9). As a starting point, they utilised the Cochrane derived models of the Campbell Collaboration, Evidence for Policy and Practice Information and Co-ordinating Centre (EPPI-centre) and the Learning and Skills Development Agency.

A search of the aforementioned sites reveals that librarians are largely not "in evidence". As the emphasis is primarily on higher level evidence, fields with approaches considered to be lower forms of evidence tend to be overlooked. Hence, there is little library related content, and it appears much of the literature remains within library circles. The VOCED database contains library and related content, but minimal material on conceptual frameworks for library evidence in the evolving vocational context, what it is, or appropriate methodologies for research. EBL needs a higher profile, with contributions related to the host organisation, if libraries are going to be appropriately recognised in the increasingly accountable, higher level evidence, measured, VET environment.

\section{Conclusion}

In this paper the authors set out to raise the profile of vocational libraries in an 
evidence based framework, currently overshadowed by medical and tertiary education precedent. Vocational libraries can undoubtedly benefit from a greater EBL emphasis. However, there are benefits in both directions as the vocational sector has an educational variant of evidence that may be applicable to other sectors. University education does have vocational content, and medicine is, after all, another vocation.

There is, of course, substantial literature on medical education with the usual theoretical / practical spectrum. In 1999, the Best Evidence in Medical Education Collaboration (BEME) was formed, using the Cochrane and Campbell Collaboration format, though it noted that the idea of EB medical education had been hampered by antipathy towards EBM, and that there were few good models to go on from general and higher education.

In Britain, in August 2005, the Department of Health raised some now familiar themes. Using the same basic argument as EBM - to ensure "optimum patient care and safety" and "quality of medical care" and using evidence in the form of "standards ... set ... by senior healthcare professionals", "doctors who are starting their first year after medical school ... will have to demonstrate explicitly that they are competent in a number of areas including communication and consultation skills, patient safety and teamwork, as well as the more traditional skills". This "programme based on the achievement of competence, rather than time served" ... "is just the beginning of a much wider ranging change in medical training".

Thus, even Hippocrates may be confronting, at least in part, the competency based / employability skills approach that has been the framework of the vocational sector for some time.

Partridge and Hallam ("Developing a culture of Evidence Based Practice") also note the issue of keeping university courses relevant to employers' needs in their call for other teaching and learning models to be presented and critically discussed. At Bonn in September 2005, UNESCO-UNEVOC held a seminar, involving the European Centre for Higher Education and the International Centre for Technical and Vocational Education and Training, which focused on the complex need for growing vocational content in higher education. Issues such as evidence and increased vocational content in schools and higher education, together with competencies, articulation, credit transfer, and lifelong learning issues in the knowledge based economy, were significant at this forum.

Rather than being overshadowed by medicine and university education, it seems that the evidence that has been driving vocational education for some time is now spreading into increasing vocational prominence in school and university courses, including medicine. Accordingly, the authors draw attention to the competency based evidence model.

Without a strong and pervasive research culture, librarians in VET have yet to properly embed library measures in a competency based and performance measured evidential framework. As the education systems further reconcile the conflict between liberal holistic measures at one end of the spectrum, and pragmatic employability goals at the other, the educational evidence may well be couched in terms and concepts related to competencies. Of similar relevance are the performance evaluation measures used by vocational institutions. Libraries will need to employ evidence in such a framework to prove themselves relevant to their host organisations and beyond.

\section{Acknowledgement}

A version of this paper was presented at the $3^{\text {rd }}$ International Evidence Based Librarianship Conference, held in Brisbane, Australia (October 2005). See:

$<$ http://conferences.alia.org.au/ebl2005/Ma rtina.pdf $>$. 


\section{Works cited}

Anlezark, Alison, Susan Dawe and Sarah Hayman. An Aid to Systematic Reviews of Research in Vocational Education and Training in Australia. Adelaide, National Centre for Vocational Education Research, 2005. VOCED database. 12 December 2005 $<$ http://www.ncver.edu.au/research/co mmercial/op320a.pdf $>$.

Australian Education Union, TAFE Division. Policy on the role of TAFE in education. (2001). 6 July 2005 $<$ http://www.aeufederal.org.au/Tafe/r oleoftafepolicy.pdf>.

Australian Qualifications Framework. 2005. 12 Aug. 2005

$<$ http://www.aqf.edu.au/aqfqual.htm $>$.

Berger, Margaret A. "What has a decade of Daubert wrought?" American Journal of Public Health: Supplement on Scientific Evidence and Public Policy 95.S1 (July 2005): S59-S65. 12 Aug. 2005 $<$ http://www.defendingscience.org/loa der.cfm?url=/commonspot/security/ge tfile.cfm\&PageID=2407> .

Best Evidence in Medical Education Collaboration. 2005. 1 Dec. 2005 $<$ http://www.bemecollaboration.org/>.

Brice, Anne, Andrew Booth, and Nicola Bexon. "Evidence-based librarianship: a case study in the social sciences." Libraries-a voyage of discovery. World Library and Information Congress: 71th IFLA General Conference and Council. Oslo, Norway. 14-18 August, 2005. 10 August 2005 $<$ http://www.ifla.org/IV/ifla71/papers/ 111e Brice Booth Bexon.pdf $>$.

Campbell Collaboration (C2). 2005. 12 Dec. 2005

$<\underline{\text { http://www.campbellcollaboration.or }}$ g/ $>$.
Carroll, Mary. "The well-worn path."

Australian Library Journal 51.2 (2002):

117-25. 7 July 2005

$<\underline{\text { http://www.alia.org.au/publishing/alj }}$ \$51.2/full.text/path.html>.

Dawe, Susan. "Basing policy and practice on sound evidence." Australasian Evaluation Society International Conference. Auckland, New Zealand. 18 Sept. 2003. National Centre for Vocational Education Research. VOCED database.10 May 2005 $<\underline{\text { http://www.ncver.edu.au/pubs/confs }}$ Lcp03conf.pdf $>$.

DefendingScience.org. American Journal of Public Health: Supplement on $\underline{\text { Scientific Evidence and Public Policy }}$ 95.S1 (July 2005). 12 Aug. 2005 $<\underline{\text { http://www.defendingscience.org/A }}$

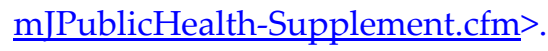

Department of Education, Science and Training. Skilling Australia: new directions for vocational education and training. Canberra:

Commonwealth of Australia, 2005. 6 July 2005 $<\underline{\text { http://www.dest.gov.au/NR/rdonlyre }}$ s/3E9602E2-C6DA-431C-BF65E053006AC4DB/2236/Skilling Australi a.pdf $>$.

Department of Health. "Major shake-up in medical training". Government News Network. 9 Aug 2005. 10 Aug. 2005 $<$ http://www.gnn.gov.uk/Content/Det ail.asp?ReleaseID $=166188 \& N e w s A r e a I$ $\underline{\mathrm{D}=2>}$

Eldredge, Jonathan D. “Evidence-based librarianship: an overview." Bulletin of the Medical Library Association 88.4 (2000): 289-302.

Evidence for Policy and Practice Information and Co-ordinating Centre (EPPI-Centre). 2005. 12 Dec.2005 $<\underline{\text { http://eppi.ioe.ac.uk/EPPIWeb/home. }}$ $\underline{\operatorname{aspx}}>$. 
Grahame-Smith, David. “Evidence based medicine: Socratic dissent." British Medical Journal 310 (1995): 1126-27. 8 July 2005

$<\underline{\text { http://bmj.bmijournals.com/cgi/conte }}$ nt/full/310/6987/1126>.

Groundwater-Smith, Susan. "Evidence based practice - towards whole school improvement." Annual Conference Australian Association for Research in Education. Sydney. 4-7 Dec 2000. 7 July 2005

$<\underline{\text { http://www.aare.edu.au/00pap/gro00 }}$ 303.htm>.

Ioannidis, John P.A. “Why most published research findings are false." $\underline{P L O S}$ Medicine (Pre-issue), 2.8: e124 (2005): 1-6. 20 Aug. 2005

$<$ http://www.pubmedcentral.nih.gov/ articlerender.fcgi?tool=pubmed\&pub medid $=16060722>$.

Kearns, Peter. VET in the 21 $21^{\text {st }}$ century global knowledge economy: an overview of international developments in Vocational Education and Training. Kambah, ACT: Peter Kearns and Associates, 2004. 12 Aug. 2005

$<$ http://www.dest.gov.au/NR/rdonlyre s/2E5924CC-3463-4956-9D103CFEEABE3026/6342/VET Global Kn owledge Economy Peter Kearns.rtf $>$.

Learning and Skills Development Agency (LSDA). 2005. 12 Dec. 2005

$<$ http://www.lsda.org.uk/home.asp $>$.

Macauley, Peter. "The doctoring of evidence based librarianship". Evolution of evidence: global perspectives on linking evidence with practice. $3^{\text {rd }}$ International Evidence Based Librarianship Conference, 16-19 Oct 2005. Brisbane, Queensland. 12 Aug. 2005 $<$ http://conferences.alia.org.au/ebl2005 keynoteabstracts.html\#Macauley>.

McDonald, Rod. Towards evidence-based vocational education and training. Adelaide, National Centre for
Vocational Education Research, 1999.

VOCED database. 10 May 2005

$<\underline{\text { http://www.ncver.edu.au/research/pr }}$ oj/nr9002.pdf $>$.

National Council for Vocational Education Research. 2005. 12 Dec. 2005

$<$ http://www.ncver.edu.au/>.

National Training Information Service.

2005. 12 Aug. 2005

$<$ http://www.ntis.gov.au/>.

Partridge, Helen and Gillian Hallam. "The Double Helix: a personal account of the discovery of the structure of [the Information Professional's] DNA." Australian Library and Information Association (ALIA) Biennial Conference. Gold Coast, Australia. 2124 September 2004. 29 June 2005 $<$ http://conferences.alia.org.au/alia200 4/pdfs/partridge.h.paper.pdf>.

---. "Developing a culture of evidence based practice within the library and information profession: the impact of library science education. A teaching and learning model from the Queensland University of Technology." IFLA World Library and Information Congress, Division VII Management and Marketing Section. 2005. 12 Aug. 2005 $<$ http://eprints.qut.edu.au/archive/000 01973/01/1973.pdf $>$.

Smith, Elizabeth and Cecily Martina.

"Keeping the dough rising: considering information in the workplace with reference to the bakery trade". In Danaher, P.A., C. Macpherson, F. Nouwens, \& D. Orr (eds.). (2004). Lifelong learning: whose responsibility \& what is your contribution?: refereed papers from the $3^{\text {rd }}$ international lifelong learning conference. Rockhampton, Qld.: Central Queensland University Press.

Smith, Richard. "Medical journals are an extension of the marketing arm of pharmaceutical companies." PLoS Medicine, 2.5: e138 (2005): 1-6. 8 July 
2005

$<$ http://medicine.plosjournals.org/perl serv/?request=get-

document\&doi=10.1371/journal.pmed. 0020138>.

Straus, Sharon E. and Finlay A McAlister.

"Evidence based medicine: a commentary on common criticisms" CMAJ/JAMC 163.7 (2000): 837-841 12 Aug 2005

$<$ http://www.cmaj.ca/cgi/reprint/163/7 837>.

Thomson, Peter, Alison Anlezark, Susan Dawe, and Sarah Hayman. The Mature-Aged and Skill Development Activities: a Systematic Review of Research. Adelaide, National Centre for Vocational Education Research, 2005. VOCED database. 12 Dec. 2005 $<$ http://www.ncver.edu.au/research/co mmercial/op320b.pdf $>$.

Todd, Ross. "Transitions for preferred futures of school libraries: Knowledge space, not information place Connections, not collections Actions, not positions Evidence, not advocacy". IASL Conference. Auckland, New Zealand. 9-12 July 2001. 30 March 2005 $<$ http://www.iaslslo.org/virtualpaper2001.html>.

UNESCO-UNEVOC International Centre for Technical and Vocational Education and Training. Vocational Content in Mass Higher Education? Responses to Challenges for the Labour Market and the Work-Place. Bonn, 8-10 September 2005. 10 Oct. 2005

$<$ http://portal.unesco.org/education/en lev.phpURL ID $=38189 \&$ URL DO=DO TOPI C\&URL SECTION=201.html>.
VOCED database. 2005. 12 Dec. 2005 $<$ http://www.voced.edu.au/index.htm $>$.

Wagner, Wendy. "The perils of relying on interested parties to evaluate scientific quality." American Journal of Public Health: Supplement on Scientific Evidence and Public Policy 95.S1 (July 2005): S99-S106. 12 Aug. 2005

$<$ http://www.defendingscience.org/loa der.cfm?url=/commonspot/security/ge tfile.cfm\&PageID=2412>. 